\title{
The Need Analysis of Interactive Multimedia Program as the Medium for Volleyball Subject
}

\author{
Muhammad Suhairi* \\ Health Physical Education and Recreation \\ IKIP PGRI Pontianak \\ Pontianak, Indonesia \\ *suhairim27@gmail.com
}

\author{
James Tangkudung, Moch. Asmawi \\ Physical Education \\ Universitas Negeri Jakarta \\ Jakarta, Indonesia \\ james24061952@gmail.com, asmawi.moch@yahoo.co.id
}

\begin{abstract}
Based on the results of preliminary observations, researchers found that, in the training process, students had not used a multimedia approach. The purpose of this study was to determine the level of need in volleyball exercise. The research method used was descriptive qualitative method. The subjects and objects of this study were 60 students who participated in the student activity unit for volleyball sports. The place for conducting this research was IKIP PGRI Pontianak. The results showed that: 1) The trainer had never used an interactive multimedia approach in the training process, 2) The exercise model of the volleyball used had not varied, 3) It is necessary to develop various volleyball skill training models, 4) There is a need for a multimedia-based volleyball skill training model.
\end{abstract}

\section{Keywords: multimedia, training model, volleyball}

\section{INTRODUCTION}

The use of media in the world of education is inseparable from technological touch and progress [1]. Many benefits can be gained by students in the use of multimedia technology, because multimedia technology is able to overcome difficulties when learning or training. The use of multimedia aims to overcome the limitations of space, time, and distance during the learning and training process [2]. Multimedia technology can be a companion of the student learning process [3].

Article 1 Paragraph 1 of the Law of the Republic of Indonesia Number 3 of 2005 concerning the Sports System, explains that sports is all aspects related to sports that require regulation, education, learning, coaching, development and supervision. Sports achievement is a sport that fosters and develops sportsmen in a planned, tiered, and sustainable manner through competencies to achieve achievement with the support of science and technology [4]. In accordance with the law that the research wants to find out more about the use of multimedia technology in task training in the unit student activity IKIP PGRI Pontianak. Based on this description, the researchers felt the need to conduct this research in order to develop a prototype of an interactive multimedia program to assist volleyball training activities in the Volleyball Sports Student Activity Unit. Besides this research is also needed in the development of interactive multimedia programs in accordance with the needs and demands of the field. Thus, data and information will be obtained directly from students who take volleyball exercises about their needs for an interactive multimedia program in volleyball skills training activities that are suitable for presentation through interactive multimedia programs.

There are a number of problems that want to be answered through this study, including: a) whether the trainer has ever applied interactive multimedia use in the volleyball training process, b) whether the training model applied has varied, c) whether it is necessary to develop various volleyball training models, d) whether students feel the need for an interactive multimedia program in volleyball training. This research will be very useful for students, athletes, Volleyball Sports trainers IKIP PGRI Ponitanak in the development of interactive multimedia programs for volleyball training in accordance with the needs in the field. The purpose of this study was to determine the level of need in volleyball exercise.

\section{A. Exercise Model}

The exercise model is an exercise used by the trainer or teacher to provide different material to athletes or students to avoid boredom and boredom in practice. Each trainer must think about variations in training in the preparation of the training program, because it will affect the activity and interest in following the exercise activities [5]. Variations of training are carried out to prevent the possibility of boredom, the trainer must be creative and clever in finding and applying variations of practice [6]. In an effort to overcome boredom and monotonous training, a creative trainer is expected to have a lot of knowledge and various types of exercises that can be varied and alternately periodic [7].

In simple terms exercises can be formulated, namely all the power and efforts to improve the overall physical condition with a systematic and repetitive process with increasing training load, and intensity [8]. Someone does the exercise because it is a form of effort to achieve a goal. Exercise is a person's effort to improve the improvement of an organism and its function to optimize sports performance and performance [9]. In the game volleyball coach is one of the factors to help improve the ability of athletes. The success of a coach depends on how to play optimally [10]. Therefore the coach should be able to master the sub-disciplines to support the profession in the success of athletes [11]. Thus the use of sports science and technology pathways becomes increasingly important, because the study of fields of science that are closely related to sports 
deliver messages to the public [21]. Another opinion states that multimedia is "multimedia is the use of a computer to present and combine text, graphics, audio, and video with links and tools that let the user navigate, interact, create, and communicate [22].

Multimedia has several categories according to Daryanto dividing multimedia into two categories, namely linear multimedia and interactive multimedia [23]. Linear multimedia is a multimedia that is not equipped with any controller that can be operated by users. Interactive multimedia is a medium that is equipped with a controller that can be operated by users so that users can choose what they want for the next process.

Apart from differences of opinion about the definition of multimedia, there are interactions that are interpreted as a prominent feature in multimedia that enables active learning [24]. Active learning not only allows students to see or hear but also do something. In multimedia techniques, doing something can take the form of: responding to questions presented by the computer or active in simulations provided by the computer.

An interactive multimedia program is a multimedia program that is designed so that it can interact with its users [25]. Interaction can be in the form of response, feedback on the form of the form of practice applied. In this case students can find out whether the form of training they are doing is correct or not.

Multimedia has many benefits in life, especially in the world of education both students, teachers, and coaches [26]. Because with multimedia learning can be delivered easily, from something abstract to more concrete, making it more interesting, more interactive, easy to understand, clear and can be done when only and anywhere that involves the senses, especially the ears and eyes, is used to absorb information.

Multimedia systems have several advantages [27], namely reducing the time and space used to broadcast and display documents in electronic form compared to paper forms; increase productivity by avoiding the loss of faile; giving documents access at the same time and displayed on the screen; provide multidimensional information in the organization; reduce time and costs in making photos, and provide speed facilities for information needed with visual interaction. In addition, the benefits of multimedia are enabling dialogue, enhancing creativity, facilitating collaboration, enriching experiences, and improving skills.

\section{RESEARCH METHODOLOGY}

This research was conducted through a survey of respondents determined as a sample. This study uses total sampling, making all students who take part in volleyball student activity units as a sample. The study population was students who participated in the volleyball IKIP PGRI Pontianak sports activities, totalling 60 students as respondents. The research method uses descriptive qualitative methods, with data collection through questionnaires and interviews. Questionnaire is given to students who take part in volleyball activities. While the interviews were conducted with the teacher. The field study was conducted in the first week of March 2018. Data was collected through a needs analysis of text, graphic imation, and others that are friended into digital files, used to convey or 
questionnaire consisting of male and female students who were members of the volleyball student activity unit.

Efforts to equalize perceptions about the meaning of interactive multimedia in volleyball training, before giving questionnaires to respondents, were first shown several prototypes of interactive multimedia programs for volleyball training activities. Students are given the opportunity to try the program with a prototype sample swim skills course. The students also explained about the various types of multimedia. After being given an explanation, students were given a questionnaire containing questions about their need for an interactive multimedia-based program in volleyball skills training.

The study was conducted for 4 months, namely between March and the end of June, with activities that included a literature study on relevant issues, design preparation, review and design revision, instrument development, data collection, data analysis, report writing, and research results. The data collected were analysed qualitatively and quantitatively, by giving a percentage of the results of the respondents' answers.

\section{RESULTS AND DISCUSSION}

Data collection was conducted on the first week of March 2018. Respondents in this study consisted of 60 students, who passed the volleyball basic movement course and 2 lecturers of volleyball courses at IKIP PGRI Pontianak. This needs analysis is carried out by distributing needs analysis questionnaires with model development questions, analysing the conditions of previous exercises that have been carried out and the use of the media in the training and learning process.

TABLE I. DATA RESULTS ANALYSIS OF NEEDS

\begin{tabular}{|l|l|l|l|l|}
\hline No. & \multicolumn{1}{|c|}{ Question } & Score & $\begin{array}{c}\text { Total } \\
\text { Score }\end{array}$ & \% \\
\hline 1. & $\begin{array}{l}\text { Are you ever attended } \\
\text { volleyball lectures. }\end{array}$ & 60 & 60 & 100 \\
\hline 2. & $\begin{array}{l}\text { Are you a volleyball player } \\
\text { go you master all volleyball } \\
\text { game techniques }\end{array}$ & 24 & 60 & 40 \\
\hline 4. & $\begin{array}{l}\text { Whether in training the trainer } \\
\text { uses a varied model }\end{array}$ & 25 & 60 & 41,67 \\
\hline 5. & $\begin{array}{l}\text { Is the model used by the trainer } \\
\text { varied }\end{array}$ & 20 & 60 & 33,33 \\
\hline 6. & $\begin{array}{l}\text { Have the coach ever provided } \\
\text { interactive multimedia to help } \\
\text { you practice }\end{array}$ & 0 & 60 & 0 \\
\hline 7. & $\begin{array}{l}\text { Do you feel the need to develop } \\
\text { volleyball skills training models }\end{array}$ & 60 & 60 & 100 \\
\hline 8. & $\begin{array}{l}\text { Do you feel the need for } \\
\text { interactive media that helps you } \\
\text { better understand the game of } \\
\text { volleyball and better master the } \\
\text { skills }\end{array}$ & 60 & 60 & 0 \\
\hline
\end{tabular}

Based on the results of the needs analysis in the above table, there are several important points that are key to the need for development. Among other things, that 1) out of 60 students $100 \%$ of students stated that the trainer never provided interactive multimedia to help practice, 2) out of 60 students $41.67 \%$ of students stated that the model used by the trainer still did not vary, 3) out of 60 students, $100 \%$ stated that there was a need to develop a volleyball skills training model, 4) out of 60 students, $100 \%$ students felt the need to develop a multimedia interactive volleyball skills training model.

Most students are very positive with the use of interactive multimedia in learning [28]. Interactive multimedia products such as volleyball games were declared fit for use in volleyball learning and training [29]. While based on observations made by researchers, it has not been found that there are media practices in the form of video or interactive, and the model used is still using conventional drill models. So it is necessary to develop a multimedia-based volleyball training model.

In essence, both students and teachers are of the opinion that multimedia is an interesting learning medium and is very suitable for presenting models of variations in the basic movements of volleyball exercises. Besides that they also argue that interactive multimedia programs can help expedite the learning process and volleyball training. Thus they feel the need to utilize multimedia programs in learning and training activities to improve volleyball playing skills. The development of multimedia in the field of sports information is needed as an increase in sports information systems [30].

\section{CONCLUSION}

Based on the formulation of the problem that will be answered from this research and analysis of research results, some conclusions can be drawn as follows:

- Have never applied the use of interactive multimedia programs in the volleyball training process, or in the learning of basic volleyball movements. Students and teachers feel the need for an interactive multimedia program to support learning activities and exercises to improve volleyball skills.

- Students and teachers need a variety of volleyball training models that are presented in interactive multimedia clashes in the introduction of volleyball game skills.

- It is necessary to develop various models of volleyball skill training using multimedia, to make it easier to understand training material and in volleyball learning.

- To make it easier to understand the training material and make it easier for students to quickly provide feedback to students to feel the need for an interactive multimedia program in volleyball training.

\section{ACKNOWLEDGMENT}

Health and Recreation Physical Education Study Program IKIP PGRI Pontianak. Ministry of Research, Technology and Higher Education.

\section{REFERENCES}

[1] A. Gallace and C. Spence, Social touch. In Affective Touch and the Neurophysiology of CT Afferents, 2016, pp. 227-238 
First Superhuman Sports Design Challenge," First International Symposium on Amplifying Capabilities and Competing in Mixed Realities, 2018.

[17] M. Yunus, Volleyball Choices Sports, Jakarta: Depdikbud, Dirjen Dikti, 1992.

[18] Sukintaka, Volleyball Game, Jakarta: Depdikbud, 1983.

[19] N. Ahmadi, Volleyball Sports Guide, Surakarta: Era Pustaka Utama, 2007.

[20] R.E. Mayer, "Research--Based Principles for Designing Multimedia Instruction Overview of Multimedia Instruction," Acknowledgement and Dedication, pp. 1-12, 2014.

[21] N.S. Rahayu, Multimedia Design, Issue 1 Ministry of Education and Culture, 2013.

[22] F.T. Hofstetter, Multimedia Literacy: Third Edition, McGraw-Hill Irwin, 2001

[23] Daryanto, Learning Media, Yogyakarta: Gava Media, 2013.

[24] P.R. Albion and I.W. Gibson, "Designing multimedia material using a problem-based learning design," In Proceedings of the 15th Annual Conference of the Australasian Society for Computers in Learning in Tertiary Education, pp. 39-47, 1998

[25] M.J. Green and B.H. Levi, "Development of an interactive computer program for advance care planning," Health Expectations, vol. 12(1), pp 60-69, 2009.

[26] K. Aoyagi, K. Ishii, A. Shibata, H. Arai, H. Fukamachi, and K. Oka, "Cooperative coaching: Benefits to students in extracurricular schoo sports," Journal of Physical Education and Sport, vol. 16(3), pp. 806, 2016.

[27] P.K. Atrey, M.A. Hossain, A. El Saddik, and M.S. Kankanhalli, "Multimodal fusion for multimedia analysis: A survey," Multimedia Systems, vol. 16(6), pp. 345-379, 2010.

[28] K. Komalasari and R. Rahmat, "Living Values Based Interactive Multimedia in Civic Education Learning," International Journal of Instruction, vol. 12(1), pp. 113-26, 2019.

[29] T.S. Haryanto, W.D. Dwiyogo, and S. Sulistyorini, "Development Of Bolavoly Game Learning Using Interactive Media In State 6 State SMP in Situbondo District, 2015.

[30] P. Gao, "Application Research on Multimedia Information Technology in the Universities Physical Teaching," The Open Cybernetics \& Systemics Journal., 2015.

[16] G. Chernyshov, K. Ragozin, J. Chen, and K. Kunze, "DubHap : A Sensory Substitution Based Superhuman Sport. In Proceedings of the 